\title{
Clinical significance of the resistin in clinical practice
}

\author{
Angel San Miguel Hernandez ${ }^{1 *}$, Maria San Miguel Rodriguez ${ }^{1}$, Angel San Miguel Rodriguez ${ }^{1}$, Sara Martin Armentia ${ }^{2}$ and Jesus Pachon $^{3}$ \\ ${ }^{1}$ Clinical Analysis Service and Research Unit. Rio Hortega University Hospital, Valladolid, Spain \\ ${ }^{2}$ Pediatric Service. Rio Carrion Hospital, Palencia, Spain \\ ${ }^{3}$ Faculty of Health Sciences. International University Isabel I de Castilla
}

\begin{abstract}
Resistin is a protein composed of 108 amino acids that is named after its supposed effect on the induction of insulin resistance in mice. It has a very important role as a regulator of adipogenesis, whereby it acts on adipose tissue. Associated with obesity, it is also known to participate in different metabolic processes, besides acting as a proinflammatory factor promoting the production of inflammatory cytokines and increasing the expression of cellular adhesion molecules. High levels of resistin have been associated with chronic inflammatory diseases such as rheumatoid arthritis and inflammatory bowel disease, significantly influencing the pathophysiology of atherosclerosis and endothelial cell damage. On the other hand, there are studies that support a role of resistin, not yet well known, with proangiogenic, antiapoptotic and even metastatic effects that could contribute to the appearance of different types of cancer, many of them related to obesity.
\end{abstract}

\section{Introduction}

The resistin, whose specific biological effects have not yet been elucidated, is known to participate in different metabolic processes, in addition to acting as a proinflammatory factor favoring the production of inflammatory cytokines and increasing the expression of cell adhesion molecules.

High levels of resistin have been associated with chronic inflammatory diseases such as rheumatoid arthritis and inflammatory bowel disease, influencing significantly the pathophysiology of atherosclerosis and endothelial cell damage [1]. The structure of a resistin hexamer is shown in (Figure 1).

The resistin is a protein formed by 108 amino acids whose structure is crystalloid, with disulfide bonds (Cys6 and Cys2) that gets its name for its supposed effect on the induction of insulin resistance in mice, it is also known by the name of FIZZ3.

This protein has a very important function as a regulator of adipogenesis, this means that it acts on adipose tissue. It was first described in 2001 in mice, in a paper published by Steppan and his group. In their study they looked for an adipocyte factor that explained the action of thiazolidinediones (TZD) on insulin sensitivity, an action that is mediated through binding to PPAR- $\gamma$ receptors (peroxisome proliferator activated receptor- $\gamma$ ). Thus, they detailed a protein expressed and secreted by mature adipocytes, whose action is inhibited after the administration of the TZD, which they distinguished as resistin [2]. It has a size of $12.5 \mathrm{kDa}$, is within a family of proteins that

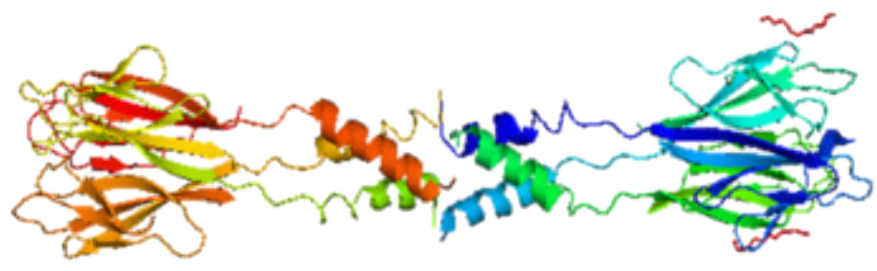

Figure 1. Structure of a resistin hexamer have a terminal residue rich in cysteine, known as FIZZ (found in inflammatory zone proteins). The same Steppan group identified other proteins similar to resistin in rodents and in humans, which they called "resistin-like molecules" (RELM). The gene encoding resistin, along with the FIZZ-3 and ADSF proteins in mice is called Retn, and the one that is transcribed as RELM- $\alpha$ or FIZZ-1 is called Retn-1, according to the International Committee for the Standardization of genetic nomenclature in mice [3].

Microarray analyzes in murine model identified resistin as a factor secreted specifically by adipocytes (ADSF, adipose secretory factor) [4]. The neutralization of its activity, through the use of anti-resistin antibodies, causes a decrease in blood glucose levels and improves the sensitivity of insulin in obese mice with resistance to it. In addition, the administration of recombinant resistin to these mice worsens glucose tolerance and induces insulin resistance [2].

In rodents, resistin interferes with the insulin signaling pathway in the main target tissues, such as adipose tissue, liver and muscle. It stimulates the production of hepatic glucose and in obese animals are found increased levels of the hormone, while these levels appear significantly diminished after the food restriction. Thus, in addition to insulin resistance, resistin can be related to other processes in the regulation of metabolic homeostasis [5]. Although the resistin of the murine and human model bear similarities, in resisting rodents, resistin is expressed mainly by adipocytes [2]. While in humans, resistin is predominantly expressed by monocytes and directly regulated by $\operatorname{PPAR} \gamma[6]$.

*Correspondence to: A San Miguel Hernández, Servicio de Análisis Clínicos, Hospital Universitario del Rio Hortega, 470012, Valladolid, Spain, E-mail: asanmi@saludcastillayleon.es

Key words: resistin, obesity, inflammation, atherosclerosis, polymorphisms, tumors

Received: September 06, 2018; Accepted: September 14, 2018; Published: September 17, 2018 
In patients with chronic kidney disease, a strong correlation between resistin levels and the state of renal function has been observed. Malysko et al, demostrated that hemodialyzed patients with renal residual function had significantly lower levels than those without residual function, supporting the hypothesis that resistin is eliminated via the kidney [7]. Adipose tissue is an endocrine organ that secretes numerous protein hormones, including adiponectin, resistin, leptin, interleukin, tumor necrosis factor, estrogen (Figure 2).

\section{Inflammation, atherosclerosis and cardiovascular disease}

It has been shown that in humans the resistin may be involved in inflammatory situations because the mononuclear cells secrete it in relevant amounts. In atherosclerotic patients, they are positively related to other markers of inflammation, such as TNF-R type II and phospholipase associated with lipoprotein A2 [8]. In human monocytes, resistin, IL-6 and TNF appear to influence each other through the NF- $\kappa B$ pathway [9]. in human adipocytes increases the expression of components of the innate immune system, including TLR2, MyD88 and NF- $\mathrm{BB}$ [10]. Kusminski et al. Have proposed that the mechanism by which resistin generates resistance to insulin is by the direct activation of TLR4, by binding to this receptor [11].

Insulin resistance and a low degree of chronic inflammation are processes that favor atherosclerosis and are associated with cardiovascular disease. Among the cytokines that are thought to participate in the two processes are the resistin. Furthermore, it has been known for some time that atherosclerosis is a cholesterol deposition disease. A large number of publications support the role of inflammation as a causative agent of atherogenesis, promoting endothelial dysfunction among others [12].

Resistin seems to participate in the pathogenesis of atherosclerosis, causing, in a manner not well known, the release of different cytokines involved in signaling pathways related to endothelial dysfunction, smooth muscle cell growth, arterial inflammation and the formation of foam cells [13].

The smooth muscle cells of the vascular tissue form a layer on the inner wall of the vessel and control blood flow by contraction-relaxation in response to different stimuli. When these cells receive a stimulus, they begin to divide, being able to cause an uncontrolled growth that triggers pathological changes in the vascular tissue structure [14].

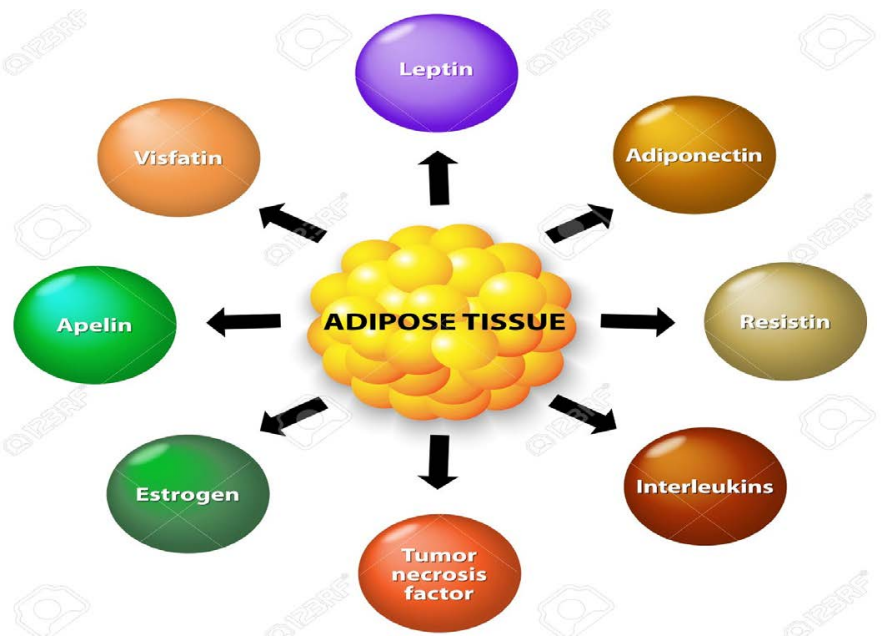

Figure 2. Different protein hormones secreted by adipose tissue
Specifically, resistin induces the expression of the messenger RNA precursor of endothelin-1 in endothelial cells, thus contributing to endothelial dysfunction, the initial stage of atherosclerosis. In addition, it significantly increases the expression of cell adhesion molecules VCAM-1 and MCP-1, molecules known to be involved in the formation of the initial atherosclerotic lesion [2]. Already in 2004, Steppan and his group, showed that resistin had proinflammatory action on smooth muscle cells inducing its proliferation. The study population of this group were diabetic patients with coronary lesions, suggesting an important role of this hormone in the restenosis of coronary lesions in this type of patients [15]. There is recent evidence that resistin is associated with atherogenic dyslipidemia and hypertension, so resistin could be a predictor of atherosclerosis, and may appear as a poor prognostic factor in patients with cardiovascular disease and/or heart failure [16].

Supporting the role of resistin in atherosclerosis, a study published in 2016 shows the existence of an inverse relationship between HDL cholesterol and resistin levels in patients with abdominal obesity. In vitro, the inhibition of HDL results in an increase in the secretion of some adipokins, among which is the resistin [17].

A study published this year, compares the serum concentration of resistin, as well as its expression in tissues in the form of mRNA, with that of different cytokines related to it such as IL1B, IL6, IL8, TNFalfa and IL12, between healthy patients and patients presenting type 2 diabetes mellitus and coronary disease. In the control group, detectable levels of all cytokines were found, with a statistically significant relationship between them. Compared with the group of sick patients, they showed significant differences, with the exception of IL12, both in the concentration and mRNA expression. In addition, the relationship between resistin and some cardiovascular risk factors related to insulin resistance and low-grade systemic inflammation, such as body mass index and the concentration of HDL cholesterol and triglycerides, were studied. The relationship found was statistically significant, so the authors propose future studies on a combined panel of resistin and other cytokines that can predict cardiovascular risk [18].

On the other hand, there are studies that show that apparently healthy individuals in the highest quartile of resistin levels, compared with the lowest quartile, present an increased risk of myocardial infarction but not of ischemic failure. This association persists even when the levels of C-reactive protein have normalized, that is, the concentration of resistin is a factor independent of the concentration of C-reactive protein [19]. In contrast to these results, a study conducted in a postmenopausal female population, describes an independent relationship between resistin and incidence of ischemic damage [20].

Takeishi et al. found elevated serum resistin levels in individuals with heart failure, levels that correlate positively with the severity of this condition (following the NYHA functional classification) [21].

Studying hypertensive patients has shown a high concentration of serum resistin associated with the presence of peripheral arterial disease, pathology associated with an increased risk of cardiovascular disease. Supporting the results of other studies that present this adipokine as a risk factor for cardiovascular diseases, the authors conclude that according to their data, resistin can predict the risk of peripheral arterial disease, being an independent predictor in patients with hypertension [22].

In 2009, Wang and his group published another study on population with chest pain, noting that those who had Acute Coronary Syndrome (ACS) had higher serum levels of resistin than those who were classified 
in controls and stable chest angina. Within the SCA group it was found that serum resistin levels correlated significantly with those of high sensitivity C-reactive protein (hsPCR) and with leukocyte count: In the same way the resistin was correlated with the number of coronary vessels in this study demonstrating more than $50 \%$ stenosis. With these data, the authors conclude that resistin is a risk factor for ACS [23]

\section{Obesity and tumors}

Obesity is associated with cardiovascular risk factors, including inflammatory markers and adipokines, characterized by a low degree of systemic inflammation. Thus, in 2010 a study was published, in which a sample of 46 patients with morbid obesity was analyzed to evaluate the relationship between resistin levels and inflammatory markers and anthropometric parameters in these patients, making a complete nutritional and biochemical assessment. The patients were divided into two groups based on the median resistin ( $3.49 \mathrm{ng} / \mathrm{ml}$ ), group I (low values, mean: $2.60 \pm 0.5 \mathrm{ng} / \mathrm{ml}$ ) and group II (high values), mean: 5.71 $\pm 2.25 \mathrm{ng} / \mathrm{ml}$ ) [24]. Through a univariate study, the authors observed a positive relationship between resistin and inflammatory markers such as C-reactive protein or fibrinogen, as well as with LDL cholesterol or triglycerides. Thus, they support results already described in the same line as those of the Kunnari group that observed positive correlation with C-reactive protein (CRP). In addition, Qi et al, saw that there was also a positive correlation between resistin and certain inflammatory markers such as PCR and fibrinogen $[25,26]$.

Excess weight is associated with different pathologies derived from it. In addition, there is growing evidence at the epidemiological and experimental level that indicates that chronic exposure to high plasma levels of insulin, increases the risk of certain types of tumors (colon, endometrium), possibly by the hypermetabolism that provides energy for cell division [27].

Resistin, in addition to being related to insulin resistance, can act as a proinflammatory, pro-angiogenic, antiapoptotic molecule and is also believed to have metastatic activity. Accumulated evidence suggests a role for resistin as a risk and prognostic (and potentially diagnostic) biomarker in cancer [28].

The proinflammatory state induced by obesity, especially of the visceral type, could act as an activator of different responses, ultimately leading to the appearance of cancer [29]. In 2011, an-in vitro study was published, the results of which suggest that the PI3K / Akt signaling pathway, implicated in cell proliferation, could be used by resistin to induce cancer [30]. In vivo studies, in addition to the risk of diseases associated with obesity, there is a relationship between resistin and breast, colorectal and endometrial cancer, among others, which supports the results obtained in vitro [31-33]. One of the current lines of research on resistin seeks to find and/or understand the mechanisms that involve it in different types of tumors, some of them associated with obesity.

\section{Other processes}

Resistin is thought to be also related to the pathogenesis of rheumatoid arthritis, finding this hormone in the plasma and synovial fluid of patients with RA. However, controversial studies with resistin values have been found in patients with rheumatoid arthritis since they are sometimes similar to the values found in healthy controls. In other studies it has been observed that resistin values were greater in the synovial fluid than in the serum, suggesting that the systemic values of adipokines do not have to be reflected in the joint. This discrepancy may simply be due to increased permeability of the inflamed synovial membrane or be an epiphenomenon [34].

In treatment with infiximab (TNF- $\alpha$ antagonist) in rheumatoid arthritis and inflammatory bowel disease, resistin levels decrease. In addition, this hormone correlates with the severity of sepsis, with inflammatory cytokine levels and with insulin resistance in critically ill patients [35].

The role of resistin in systemic lupus erythematosus (SLE) has also been studied, and although the results are controversial, there are studies that support the existence of correlation between them. Baker et al found a correlation in their study between serum levels of resistin and the degree of inflammation in patients with SLE [36]. In these diagnosed patients, significantly higher levels of resistin were found. In determinations such as the estimation of the glomerular filtration rate, homocysteine and the duration of the disease, they found a positive correlation with serum resistin levels. In addition, among patients diagnosed with SLE, those cases that presented calcification of the coronary artery showed significantly higher values of serum resistin. Thus, although the mechanism that causes an increase in resistin in patients with SLE is unknown, they propose that processes such as the state of renal function, the release of inflammatory mediators in the production of resistin or alterations in the distribution of fat, participate together in said mechanism [37].

\section{Determination of the concentration of southern resistina}

For the determination of levels of serum resistin in humans there are commercial kits for use in research (eBioscience, Thermofisher, BioVendor, Phoenix Pharmaceuticals, among others). The technique provided is an enzyme immunoassay (ELISA), but the lack of standardization means that there are differences between these commercial kits. The intraassay coefficient of variation $(\mathrm{CV})$, provided by the manufacturer, can vary from $4.7 \%$ to values close to $10 \%$. The interassay CV may range between approximately $7.6 \%$ and $15 \%$. The minimum concentration of resistin that can be detected by the commercial kits, although varies according to the manufacturer, can reach $0.1 \mathrm{ng} / \mathrm{mL}$.

The resistin can circulate freely although its mature form tends to form oligomers of different molecular weight, forms have been detected from 55 to $660 \mathrm{kDa}$, aspect that complicates the interpretation of the results, there being no consensus in the scientific literature [38]. Through experiments with size exclusion chromatography, already in 2005 the existence of different isoforms of human resistin was evidenced, coinciding with the results obtained in mice by Patel and his group, which show the existence of hexamers with a molecular weight of $55 \mathrm{kDa}$ and $45 \mathrm{kDa}$ trimers [39]. In Wistar rats, there is also a shorter isoform, $389 \mathrm{bp}$ compared to 529 of the original form, generated by alternative mRNA splicing, called s-Resistin (short resistin), which represents the intracellular non-secreted form [40]. In 2004, Nohira and her group isolated a cDNA from a smaller human resistin isoform by analyzing the expression of this hormone in different tissues. A deletion of $78 \mathrm{bp}$, which corresponds to exon 2, is what characterizes this isoform and causes the truncation of the protein [41]. The existence of isoforms, in addition to affecting the determination of resistin, is a handicap when comparing blood levels with kits from different manufacturers.

In a study of 2013, studying cell lines that constitutively express different isoforms, determined the specificity of the antibodies used 
for the determination of resistin levels by Western blot (WB) and immunofluorescence. Some of these antibodies revealed specificity in Western blot but not in immunofluorescence and others showed cross-reaction in $\mathrm{WB}$, thus evidencing the need to take into account the specificity of the antibody when interpreting the results [42].

\section{Polymorphisms}

The sequence of the gene encoding the resistin, RETN gene, is known and the association of different polymorphisms with metabolic alterations has been observed.

This gene is located on chromosome 19p13.2 and occupies around 1369 bp. At least 96 single nucleotide polymorphisms (SNP) have been detected, located in the promoter, intronic and 3 'untranslated regions ( 3 'UTR) of the gene, of which at least 25 , with values of minority allele frequency $>0.05$, have been evaluated in studies of association with different diseases such as obesity, diabetes, hypertension and risk of cardiovascular disease. The results are very variable, including from the absence of association to very significant associations with various metabolic alterations, with little reproducibility in different ethnic groups.

In a study published in 2013, the association between the 3'UTR $+62 \mathrm{G}>\mathrm{A}$ polymorphism of the RETN gene and elements of the metabolic syndrome was evaluated. The allele 3'UTR $+62 \mathrm{~A}$ was 3 times more frequent in patients with metabolic syndrome than in the control group, and the individuals carrying the allele $+62 \mathrm{~A}$ showed significantly higher values of systolic blood pressure than those with genotype 3'UTR + 62G [43].

In intron 2 of the human RETN gene the SNPs $+156 \mathrm{C}>\mathrm{T}$ and + 298G > A have been linked to insulin resistance. In the 5'-promoter region of the gene, the $-394 \mathrm{C} / \mathrm{G}$ polymorphism shows a relationship with insulin sensitivity, presenting a greater frequency in diabetic patients than in controls $[44,45]$.

In a study in Japanese population in which 3 promoter SNPs were studied, correlation was found with the elevation of resistin levels, highlighting $-638 \mathrm{G}>\mathrm{A}$ and $-420 \mathrm{C}>\mathrm{G}$ that led to an increase in resistin expression in a test of In vitro transcription [46]. SNP -420C> G is also associated with an increased incidence of type 2 diabetes in several studies in Asian populations. The G / G genotype in SNP - 420 has been related in Chinese population to the development of hyperglycemia after five years of follow-up [47].

Therefore, the importance of resistin lies in participating in different metabolic processes, in addition to acting as a proinflammatory factor favoring the production of inflammatory cytokines and increasing the expression of cell adhesion molecules. It is important to highlight the importance of its value as a therapeutic target, since its high levels have been associated with chronic inflammatory diseases such as rheumatoid arthritis and inflammatory bowel disease; it also has an important influence on the pathophysiology of atherosclerosis and on endothelial cell damage.

\section{Conflict of interest}

The authors declare no conflict of interest.

\section{References}

1. Nagy K, Nagaraju SP, Rhee CM, Mathe Z, Molnar MZ (2016) Adipocytokines in renal transplant recipients. Clin Kidney J 9: 359-373. [Crossref]

2. Steppan CM, Bailey ST, Bhat S, Brown EJ, Banerjee RR, et al. (2001) The hormone resistin links obesity to diabetes. Nature 409: 307-312. [Crossref]
3. Steppan CM, Brown EJ, Wright CM, Bhat S, Banerjee RR, et al. (2001) A family of tissue-specific resistin-like molecules. Proc Natl Acad Sci USA 98: 502-506. [Crossref]

4. Kim KH, Lee K, Moon YS, Sul HS (2001) A cysteine-rich adipose tissue-specific secretory factor inhibits adipocyte differentiation. J Biol Chem 276: 11252-11256. [Crossref]

5. Nogueiras R, Gonzalez CR, Mendieta H, Lage R, Dieguez C (2005) Resistina? a new hormone expressed in adipose tissue. Rev Española Obes 3:194-211.

6. Patel L, Buckels AC, Kinghorn IJ, Murdock PR, Holbrook JD, et al. (2003) Resistin is expressed in human macrophages and directly regulated by PPAR gamma activators. Biochem Biophys Res Commun 300: 472-476. [Crossref]

7. Malyszko J, Malyszko JS, Kozminski P, Pawlak K, Mysliwiec M (2007) Elevated resistin is related to inflammation and residual renal function in haemodialysed patients. Nephrology 12: 246-253.

8. Reilly MP, Lehrke M, Wolfe ML, Rohatgi A, Lazar MA, et al. (2005) Resistin is an inflammatory marker of atherosclerosis in humans. Circulation 111: 932-939. [Crossref]

9. Bokarewa M, Nagaev I, Dahlberg L, Smith U, Tarkowski A (2005) Resistin, an adipokine with potent proinflammatory properties. J Immunol 174: 5789-5795. [Crossref]

10. Kusminski CM, da Silva NF, Creely SJ, Fisher FM, Harte AL BA (2007) The in vitro effects of resistin on the innate immune signaling pathway in isolated human subcutaneous adipocytes. J Clin Endocrinol Metab 92: 270-272.

11. Tarkowski A, Bjersing J, Shestakov A, Bokarewa MI (2010) Resistin competes with lipopolysaccharide for binding to toll-like receptor 4. J Cell Mol Med 14: 1419-1431. [Crossref]

12. Libby P, Ridker PM, Maseri A (2002) Inflammation and atherosclerosis. Circulation 105: 1135-1143. [Crossref]

13. Silswal N (2005) Human resistin stimulates the pro-in ammatory cytokines TNF-alpha and IL-12 in macrophages by NF-kappa B- dependent pathway. Biochem Biophys Res Commun 334:1092-1101.

14. T Boettger, Beetz N, Kostin S, Schneider J, Kruger M, et al. (2009) Acquisition of the contractile phenotype by murine arterial smooth muscle cells depends on the Mir143/145 gene cluster. J Clin Invest 119: 2634-2647.

15. Calabro P, Samudio I, Willerson J, Yet E (2004) Resistin promotes smooth muscle cell proliferation through activation of extracellular signal-regulated kinase $1 / 2$ and phosphatidylinositol 3-kinase pathways. Circulation 10: 3335-3340.

16. Golia E, Limongelli G, Natale F, Fimiani F, Maddaloni V, et al. (2014) Adipose tissue and vascular inflammation in coronary artery disease. World $J$ Cardiol 6: 539-554. [Crossref]

17. Song G, Wu X, Zhang P, Yu Y, Yang M, et al. (2016) High-density lipoprotein inhibits ox-LDL-induced adipokine secretion by upregulating SR-BI expression and suppressing ER Stress pathway. Sci Rep 29.

18. Menzagi C, Marucci A, Antonucci A, Bonis C De, Ortega-Moreno L (2017) Suggestive evidence of a multi-cytokine resistin pathway in humans and its role on cardiovascular events in high-risk individuals. Sci Rep 14.

19. Weikert C, Westphal S, Berger K, Dierkes J, Mohlig M, et al. (2008) Plasma resisting levels and risk of myocardial infarction and ischemic stroke. J Clin Endocrinol Metab 93: 2647-2653.

20. Rajpathak SN, Kaplan RC, Wassertheil-Smoller S, Cushman M, Rohan TE (2011) Resistin, but not adiponectin and leptin, is associated with the risk of ischemic stroke among postmenopausal women: results from the Women's Health Initiative. Stroke 42: 1813-1820.

21. Takeishi, Niizeki T, Arimoto T, Nozaki N, Hirono O, et al. (2007) Serum resistin is associated with high risk in patients with congestive heart failure-a novel link between metabolic signals and heart failure. Circ J 71: 460-464.

22. Hsu B, Lee C, Yang C, Chen Y, Wang J (2017) High serum resistin levels are associated with peripheral artery disease in the hypertensive patients. BMC Cardiovasc Disord 17.

23. Wang H, Chen DY, Cao J, He ZY, Zhu BP, et al. (2009) High serum resistin level may be an indicator of the severity of coronary disease in acute coronary syndrome. Chin Med Sci J 24: 161-166. [Crossref]

24. De Luis DA, Gonzalez Sagrado M, Conde R, Aller R, Izaola O (2010) Resistin levels and inflammatory markers in patients with morbid obesity. Nutr Hosp 25: 630-634. [Crossref]

25. Kunnari A, Ukkola O, Paivansalo M, Kesaniemi YA (2006) High plasma resistin leve is associated with enhanced highly sensitive C-reactive protein and leukocytes. $J$ Clin Endocrinol Metab 91: 2755-2760. [Crossref] 
26. Qi Q, Wang J, Li H, Yu Z Ye X, et al. (2008) Associations of resistin with inflammatory and fibrinolytic markers, insulin resistance, and metabolic syndrome in middle-aged and older Chinese. Eur J Endocrinol 159: 585-593.

27. Soto-Monge T, Lagos-Sanchez E (2009) Obesity and cancer: An epidemiological approach. Rev Medica Costa Rica Y Centroam 66: 27-32.

28. Dalamaga M (2014) Resistin as a biomarker linking obesity and inflammation to cancer: potential clinical perspectives. Biomark Med 8: 107-118.

29. Hursting S, Dunlap S (2012) Obesity, metabolic dysregulation, and cancer: a growing concern and an inflammatory (and microenvironmental) issue. Ann NY Acad Sci 1271: $82-87$.

30. Kim HJ, Lee YS, Won EH, Chang IH, Kim TH, et al. (2011) Expression of resistin in the prostate and its stimulatory effect on prostate cancer cell proliferation. BJU Int 108 : E77-83. [Crossref]

31. MJ Gunter, T Wang, M Cushman, X Xue, Wassertheil-Smoller S, et al. (2015) Circulating Adipokines and Inflammatory Markers and Postmenopausal Breast Cancer Ris. J Natl Cancer Inst 16: 107-109.

32. Danese E, Montagnana M, Minicozzi AM, Bonafini S, Ruzzenente O, et al. (2012) The role of resistin in colorectal cancer. Clin Chim Acta 413: 760-764. [Crossref]

33. Linkov F, Goughnour S, Edwards R, Lokshin A, Ramanathan R, et al. (2017) Endometrial cancer associated biomarkers in bariatric surgery candidates: exploration of racial differences. Surg Obes Relat D 13: 862-868.

34. Senolt L, Housa D, Vernerova Z, Jirasek T, Svobodova R, et al. (2007) Resistin in rheumatoid arthritis synovial tissue, synovial fluid and serum. Ann Rheum Dis 66: 458463. [Crossref]

35. Anderson PD, Mehta NN, Wolfe ML, Hinkle CC, Pruscino L, et al. (2007) Innate immunity modulates adipokines in humans. J Clin Endocrinol Metab 92: 2272-2279. [Crossref]

36. Baker JF, Morales M, Qatanani M, Cucchiara A, Nackos E, et al. (2011) Resistin levels in lupus and associations with disease-specific measures, insulin resistance, and coronary calcification. $J$ Rheumatol 38: 2369-2375.
37. Li HM, Zhang TP, Leng RX (2016) Emerging role of adipokines in systemic lupus erythematosus. Immunol Res 64: 820-830. [Crossref]

38. Gerber M, Boettner A, Seidel B, Lammert A, Ba J, et al. (2005) Serum resistin levels of obese and lean children and adolescents: biochemical analysis and clinical relevance. $J$ Clin Endocrinol Metab 90: 4503-4509.

39. Patel S, Rajala M, Rossetti L, Scherer P, Shapiro L (2004) Disulfide-dependent multimeric assembly of resistin family hormones. Science 304: 1154-1158.

40. Del Arco A, Peralta S, Carrascosa JM, Ros M, Andres A, et al. (2003) Alternative splicing generates a novel non-secretable resistin isoform in Wistar rats. FEBS Lett 555: 243-249. [Crossref]

41. Nohira T, Nagao K, Kameyama K, Nakai H, Fukumine N, et al. (2004) Identification of an alternative splicing transcript for the resistin gene and distribution of its mRNA in human tissue. Eur J Endocrinol 151: 151-154. [Crossref]

42. Fan C, Johns BA, Su Q, Kolosova IA, Johns RA (2013) Choosing the right antibody for resistin-like molecule (RELM/FIZZ) family members. Histochem Cell Biol 139: 605-613. [Crossref]

43. Arráiz N, Escalona C, Prieto C, Bermudez V, Mujica E, et al. (2013) 3'UTR +62G $>$ A polymorphism of the RETN gene coding resistin and its association with metabolic syndrome components. Med Clin (Barc) 141: 325-331. [Crossref]

44. Conneely KN, Silander K, Scott LJ, Mohlke KL, Lazaridis KN, et al. (2004) Variation in the resistin gene is associated with obesity and insulin-related phenotypes in Finnish subjects. Diabetologia 47: 1782-1788.

45. Wang H, Chu WS, Hemphill C, Elbein SC (2002) Human resistin gene: molecular scanning and evaluation of association with insulin sensitivity and type 2 diabetes in Caucasians. J Clin Endocrinol Metab 87: 2520-2524. [Crossref]

46. Azuma K, Oguchi S, Matsubara Y, Mamizuka T, Murata M, et al. (2004) Novel resistin promoter polymorphisms: Association with serum resistin level in Japanese obese individuals. Horm Metab Res 36: 564-570.

47. Cho YM, Youn B-S, Chung SS, Kim KW, Lee HK, et al. (2004) Common genetic polymorphisms in the promoter of resistin gene are major determinants of plasma resistin concentrations in humans. Diabetologia 47: 559-565.

Copyright: (C2018 San Miguel-Hernández A. This is an open-access article distributed under the terms of the Creative Commons Attribution License, which permits unrestricted use, distribution, and reproduction in any medium, provided the original author and source are credited. 